\title{
Viability of Sirococcus clavigignenti-juglandacearum Conidia on Exoskeletons of Three Coleopteran Species
}

\author{
J. E. Stewart, S. Halik, and D. R. Bergdahl, The Rubenstein School of Environment and Natural Resources, Aiken \\ Center, University of Vermont, Burlington 05405
}

\begin{abstract}
Stewart, J. E., Halik, S., and Bergdahl, D. R. 2004. Viability of Sirococcus clavigignentijuglandacearum conidia on exoskeletons of three coleopteran species. Plant Dis. 88:1085-1091.

Butternut canker, caused by Sirococcus clavigignenti-juglandacearum, is the primary cause of decline of butternut (Juglans cinerea). Conidia of the fungus have been isolated from several insect species. The vector potential of three species of Coleoptera, Astylopsis macula, Eubulus parochus, and Glischrochilus sanguinolentus, was studied during 2001 and 2002. Beetles were collected, rinsed, and artificially inoculated with conidia. All three species carried viable conidia up to 16 days. The mean number of conidia carried per beetle in 2001 was as follows: 3.21 million at $0 \mathrm{~h}$ to 11,371 at $384 \mathrm{~h}$ for A. macula; 3.91 million at $0 \mathrm{~h}$ to 57 at $384 \mathrm{~h}$ for E. parochus; and 355,742 at $0 \mathrm{~h}$ to 314 at $384 \mathrm{~h}$ for G. sanguinolentus. In 2002, the numbers were: 1.42 million at $0 \mathrm{~h}$ to 2,814 at $384 \mathrm{~h}$ for $A$. macula; 1.29 million at $0 \mathrm{~h}$ to 85 at $384 \mathrm{~h}$ for E. parochus; and 72,342 at $0 \mathrm{~h}$ to 0 at $192 \mathrm{~h}$ for $G$. sanguinolentus. Using scanning electron microscopy, conidia were observed on the abdomen, thorax, and legs of artificially inoculated individuals of each species and on the thorax and abdomen of field-collected A. macula and E. parochus. These data suggest that all three species are potential vectors of $S$. clavigignenti-juglandacearum; however, A. macula and E. parochus may be more effective vectors.
\end{abstract}

Additional keywords: Conotrachelus juglandis, nitidulid, vector

Butternut canker, caused by the fungus Sirococcus clavigignenti-juglandacearum Nair, Kostichka, \& Kuntz, is a major factor in the decline of butternut (Juglans cinerea L.), an eastern hardwood species of value commercially and ecologically. The fungus produces hyphal pegs (stromatal columns) that lift and split the outer bark to expose pycnidia, which exude conidia in a sticky matrix, especially during wet conditions. Conidia are released by rain splash and may be carried in mist droplets by wind. These wind-disseminated conidia are known to travel as much as $40 \mathrm{~m}$ from infected trees $(10,16)$.

Spore dissemination via rain splash and wind is a random event (13); thus, other means of conidial dissemination are thought to be involved in the rapid spread of S. clavigignenti-juglandacearum throughout the range of butternut. Tisserat and Kuntz (18) showed that the concentration levels of airborne conidia reached near 0 at $10 \mathrm{~m}$ from the inoculum source; however,

Corresponding author: J. E. Stewart

E-mail: janestewart@fs.fed.us

Current address for J. Stewart: Forestry Sciences Laboratory, USFS Rocky Mountain Research Station, Moscow, ID 83843

Accepted for publication 21 May 2004

Publication no. D-2004-0727-04R

(C) 2004 The American Phytopathological Society healthy butternuts become infected even though no other butternuts are located within $10 \mathrm{~m}$ of infected trees $(11,12)$. Therefore, it is thought that animals, such as birds, squirrels, or insects that specifically target butternut, may be involved in long distance dispersal of the fungus.

Surveys of possible insect vectors of the butternut canker fungus revealed that over 35 families of insects are associated with butternut trees (9). Several Coleopteran species have been shown to carry viable conidia of $S$. clavigignenti-juglandacearum $(5,6,9)$. Beetle species commonly found on butternut in the Champlain Valley of Vermont include: Astylopsis macula (Say) (Cerambycidae), Eubulus parochus (Herbst) (Curculionidae), Conotrachelus juglandis LeConte (Curculionidae), and Glischrochilus sanguinolentus (Olivier) (Nitidulidae). A. macula and E. parochus feed and oviposit on branches and stems of dead or dying butternuts. C. juglandis, the butternut curculio, creates feeding and oviposition wounds on foliage, twigs, and fruit of healthy butternuts. G. sanguinolentus has been observed burrowing into wounds and oviposition sites of C. juglandis and in cankers on diseased trees (6).

Field studies in Vermont concluded that some of these insects frequently carry high numbers of conidia (6). In 1999, 74\% of $A$. macula and $37 \%$ of E. parochus carried conidia, compared with $7 \%$ of $C$. juglandis and G. sanguinolentus. A. macula and $E$. parochus were found to carry as many as
1.6 million and 780,000 conidia, respectively, while $G$. sanguinolentus was found to carry as many as 800 conidia (6). However, it is unknown for how long, or where, these beetles carry viable conidia of $S$. clavigignenti-juglandacearum on their exoskeletons. The objectives of this study were to determine the number of viable $S$. clavigignenti-juglandacearum conidia that artificially inoculated A. macula, E. parochus, and $G$. sanguinolentus carry externally over time and using scanning electron microscopy, determine where conidia are found on the beetles' exoskeletons.

\section{MATERIALS AND METHODS}

Beetle collection and infestation. Beetles were collected during the summers of 2001 and 2002 at two mixed northern hardwood forests in north-central Vermont. The first site was the University of Vermont research forest in Jericho, VT and the second site was the town forest in Berlin, VT. Collection methods varied depending on the species of insect. Six Lindgren funnel traps (Phero Tech, Inc., Delta, BC, Canada) baited with fresh raw bread dough were used to collect the nitidulid, G. sanguinolentus, at the Jericho site. Collection cups on the traps contained pieces of peeled Red Delicious apple used as food and moisture source to ensure survival of insects until collection. Nitidulids were collected weekly during May and June, and traps were rebaited after each collection. Trapped nitidulids were removed using sterile tweezers, placed in sterile vials, and kept on ice in a cooler for transport to the laboratory.

During the fall and spring of each year, we felled a diseased butternut tree at the Jericho site, and placed logs and branches with bark in debris piles for feeding and oviposition by A. macula and E. parochus (6). At the Berlin site, we relied on windbroken stems and limbs of butternut to attract these beetles. E. parochus was collected in early June, and A. macula was collected in mid-July. Beetles were removed from the surface of branches and logs using sterile toothpicks, placed separately in sterile collection vials, and transported on ice in a cooler to the laboratory where they were stored at $4^{\circ} \mathrm{C}$ until trials began within 2 days of collection.

In the laboratory, 100 individuals of each species were placed separately in sterile $1.5-\mathrm{ml}$ centrifuge tubes filled with $0.4 \mathrm{ml}$ of sterile distilled water (SDW), and 
the insects were swirled in the water with a vortex mixer for $15 \mathrm{~s}$. Beetles were rinsed three times and then separated into groups of five. For each species, seven groups of five insects that were used as controls were placed on sterile $1.5 \%$ malt extract agar plates for $24 \mathrm{~h}$. The remaining 13 groups of 5 insects were inoculated with $S$. clavigignenti-juglandacearum isolate 541, which was originally isolated from A. macula in Berlin, VT in 1997 and grown on at $20^{\circ} \mathrm{C}$ in the dark. Each group of beetles was placed on a plate containing sporulating pycnidia for $24 \mathrm{~h}$. More individuals were inoculated than were used for the experiment to ensure that sufficient beetles were available for use in the experiment. After inoculation, 88 beetles (56 inoculated individuals and 32 controls) were placed individually into clean $100 \times 15$ $\mathrm{mm}$ petri dishes lined with SDWmoistened filter paper ( $9 \mathrm{~cm}$ in diameter) and a food source. A. macula and E. parochus were fed autoclaved butternut sticks measuring approximately $6 \times 1 \mathrm{~cm}$. A small piece of peeled Red Delicious apple, approximately $1 \mathrm{~cm}^{3}$, served as the food $1.5 \%$ malt agar medium for 24 to 30 days

source for $G$. sanguinolentus. Food was replaced every 3 days and dishes were kept moist throughout the experiment. Two replicate trials (one per year) were conducted for each species.

Conidial quantification and germination. All insects were randomly placed in an incubator with a $12 \mathrm{~h} / 12 \mathrm{~h}$ light/dark cycle at $20^{\circ} \mathrm{C}$. At each time interval $(0,6$, $12,24,48,96,192$, and $384 \mathrm{~h}$ postinoculation), seven inoculated insects and four control insects were removed from the incubator, rinsed once as previously described, and discarded. Two loopsful of rinse water obtained from each beetle were streaked onto each of two plates of $1.5 \%$ malt extract agar. One set of streaked plates was incubated in the dark at $20^{\circ} \mathrm{C}$ for 24 days and then examined for growth of $S$. clavigignenti-juglandacearum to confirm viability of the fungus. The second set of plates was used to determine percent germination of conidia and germ tube length. These plates were placed in an incubator at $20^{\circ} \mathrm{C}$ for $30 \mathrm{~h}$. Conidial germination was halted by placing three drops of $0.1 \%$ aniline blue in $50 \%$ lactic acid onto the surface of the streaked area of each

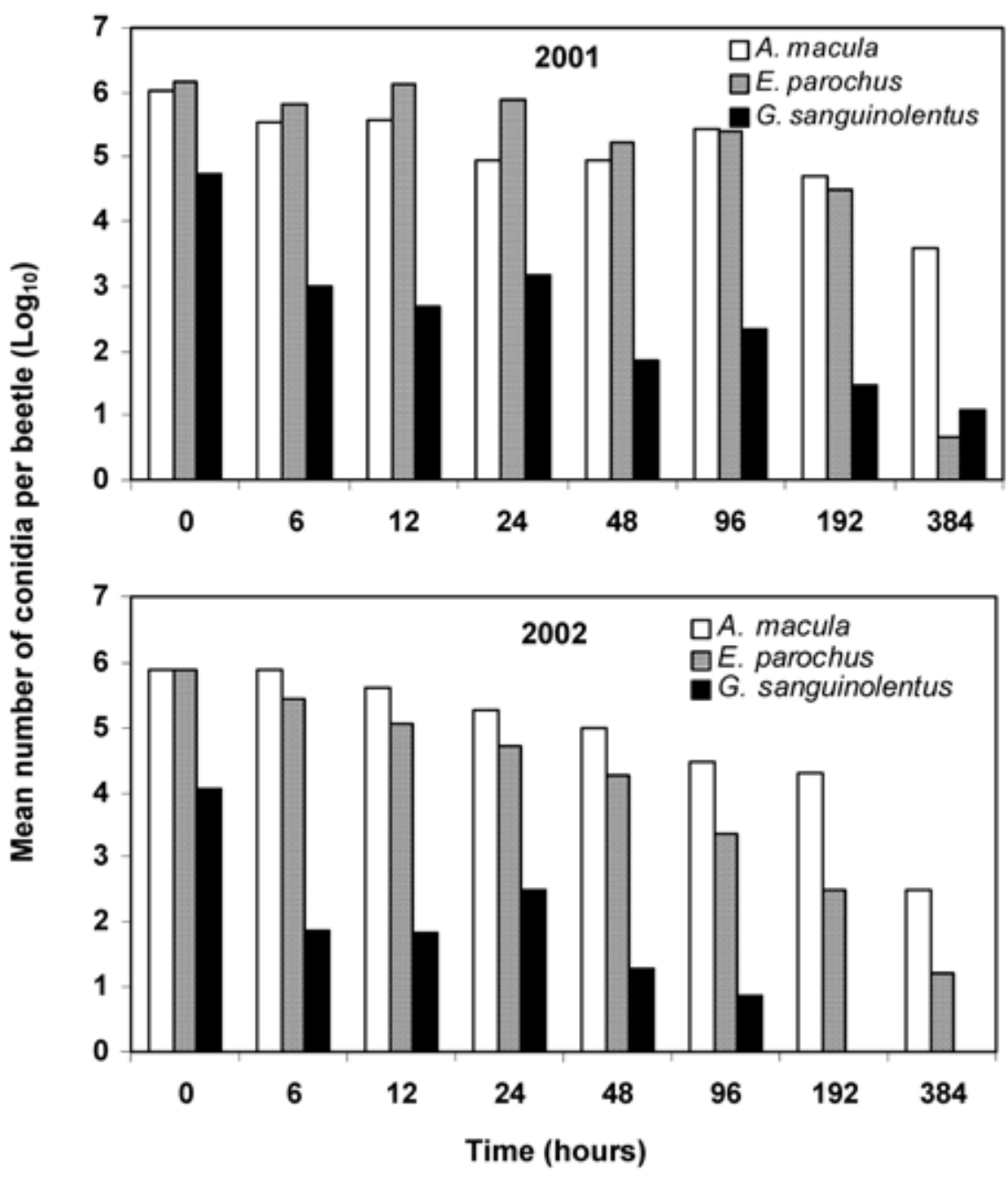

Fig. 1. Mean number of Sirococcus clavigignenti-juglandacearum conidia per beetle rinsed from artificially inoculated Astylopsis macula, Eubulus parochus, and Glischrochilus sanguinolentus at each sampling time interval (hours postinoculation) in 2001 and 2002. plate, and each stained area was covered with a $22 \times 40 \mathrm{~mm}$ glass microscope cover slip. Ten randomly assigned fields in a grid pattern at $\times 400$ were observed on each plate to determine spore germination rate. A conidium was considered germinated if its germ tube length was at least one-half the length of the spore. Lengths of 20 germ tubes per plate (two from each field) were measured at $\times 400$ to the nearest micrometer.

The remaining rinse water was stained with $0.1 \%$ aniline blue in $50 \%$ lactic acid to prevent germination and stored at $4{ }^{\circ} \mathrm{C}$ until processed. A microscope slide was prepared using the stained rinsed water and examined at $\times 100$. If conidia were observed, we estimated the concentration of conidia in the centrifuge tube using a hemacytometer (19). When the number of conidia counted on the hemacytometer was $<10$, tubes were centrifuged, $0.2 \mathrm{ml}$ of liquid were removed, and conidia resuspended with a vortex mixer. Counts were then repeated on the concentrated suspensions. With this method, the minimum number of estimated conidia was 100 per insect. In some cases, conidia were observed on the microscope slide, but none were seen on the hemacytometer grid. Beetles were considered to carry conidia if at least one conidium was found on the initial microscope slide.

Statistical analyses. Statistical analyses were conducted using SAS (SAS Institute, Cary, NC). Count data (the number of rinsed conidia at each time interval) were transformed to $\log _{10}(x+0.01)$ to normalize the variance. Analyses of covariance were used to examine differences in the overall year means (mean number of conidia rinsed from each species over all time intervals) and in the rate of decrease in number of conidia rinsed from the beetles over time among species. Polynomial regression analyses were used to develop an equation that best described the decreasing trend in numbers of conidia rinsed from each species over time. These equations were developed using the transformed count data and are not valid for time intervals after the number of conidia equals zero. For each species, data collected from the two years were not similar and were analyzed separately.

Percentage of germination and germ tube length data were analyzed using analyses of covariance. For the percentage of germination and germ tube length data sets, the overall year means and rates of change over time were compared among species. Data collected from the two years were not similar and were analyzed separately.

Location of conidia on exoskeletons. Scanning electron microscopy (SEM) was used to locate conidia on the exoskeletons of each beetle species. Field-collected beetles and beetles artificially inoculated with S. clavigignenti-juglandacearum co- 
nidia in the laboratory were examined. Five beetles of each species were collected and artificially inoculated with the methods previously described. Of the fieldcollected beetles, 10 E. parochus and $10 \mathrm{~A}$. macula were examined for spores. All field-collected and artificially inoculated beetles were stored at $0^{\circ} \mathrm{C}$ until processing.

To process for SEM, beetles were freeze-dried and mounted on aluminum stubs using silver conductive paint. Beetles were mounted to expose the ventral side of the exoskeleton, sputter coated with gold palladium alloy, and examined with a T300 scanning electron microscope (Jeol, Ltd, Peabody, MA) to determine the location of conidia on the exoskeletons. Photographs were taken for documentation.

\section{RESULTS}

Conidial counts. No S. clavigignentijuglandacearum conidia were rinsed from any of the control groups of A. macula or E. parochus. However, in 2001, a few conidia $(<100)$ were found in the rinse water from one $G$. sanguinolentus control at the 6-h and 12-h sample times. We speculate that this was caused by human error.

All artificially inoculated beetles of the three species carried S. clavigignenti-juglandacearum conidia for 16 days $(384 \mathrm{~h})$. However, the total number of conidia rinsed from exoskeletons at each time interval decreased as time increased (Fig. 1). The maximum number of conidia carried by A. macula, E. parochus, and G. sanguinolentus at $0 \mathrm{~h}$ was 14 million, 5 million, and 1 million, respectively. The mean number of conidia carried per beetle in 2001 was 3.21 million at $0 \mathrm{~h}$ and 11,371 at $384 \mathrm{~h}$ for A. macula, 3.91 million at $0 \mathrm{~h}$ and 57 at $384 \mathrm{~h}$ for E. parochus, and 355,742 at $0 \mathrm{~h}$ and 314 at $384 \mathrm{~h}$ for $G$. sanguinolentus. The mean number of conidia carried per beetle in 2002 was 1.42 million at $0 \mathrm{~h}$ and 2,814 at $384 \mathrm{~h}$ for $A$. macula, 1.29 million at $0 \mathrm{~h}$ and 85 at $384 \mathrm{~h}$ for E. parochus, and 72,342 at $0 \mathrm{~h}$ and 0 at $192 \mathrm{~h}$ for G. sanguinolentus (Fig. 1).

Both years, the overall means (mean number of conidia rinsed from the exoskeletons for all time intervals) were significantly different among species $(P=$ 0.001 ). This difference was due to $G$. sanguinolentus, which carried fewer conidia than $\operatorname{did}$ A. macula or E. parochus at $0 \mathrm{~h}$ postinoculation; however, there was no difference in the overall year means between A. macula and E. parochus ( $P=$ 0.410).

Linear equations best described the decrease in number of conidia carried over time by A. macula and E. parochus for each year, whereas quadratic equations best described the decrease in number of conidia carried over time by G. sanguinolentus for each year. Thus, we were unable to statistically compare G. sanguinolentus with the other two species (Fig. 2). Quadratic equations indicated that the decrease in number of rinsed conidia from the exoskeleton of $G$. sanguinolentus was greater at earlier sample intervals than at later intervals. The equations that best described the decrease in the number of rinsed conidia over time (transformed data) for $G$. sanguinolentus were $Y=0.0003 T^{2}$ $0.022 T+3.50\left(R^{2}=42 \% ; P=0.004\right)$ for 2001 and $Y=0.0002 T^{2}-0.057 T+3.16$ $\left(R^{2}=57 \% ; P=0.010\right)$ for 2002 in which $Y=$ number of conidia rinsed over time and $T=$ time in h (Fig. 2).

Statistical comparisons of the rate of decrease in number of rinsed conidia over time only included A. macula and E. parochus. A. macula and E. parochus did not retain conidia similarly $(P=0.006)$. $E$. parochus retained fewer conidia after 384 h than $\operatorname{did} A$. macula for both years and thus, the regression equations for E. parochus had more negative slopes. The linear equations that best described the rate of decrease in rinsed conidia over time (trans- formed data) for $E$. parochus were $Y=$ $-0.017 T+6.24\left(R^{2}=79 \% ; P=0.001\right)$ for 2001 and $Y=-0.014 T+5.21\left(R^{2}=65 \%\right.$, $P=0.001$ ) for 2002 in which $Y=$ number of conidia rinsed over time and $T=$ time in hours (Fig. 2). The linear equations that best described the rate of decrease in rinsed conidia over time (transformed data) for A. macula were $Y=-0.005 T+5.57$ $\left(R^{2}=42 \% ; P=0.001\right)$ for 2001 and $Y=$ $-0.009 T+5.71\left(R^{2}=55 \% ; P=0.001\right)$ for 2002 in which $Y=$ number of conidia rinsed over time and $T=$ time in hours (Fig. 2).

Percent germination and germ tube length. As time increased and the number of conidia on each insect decreased, it was difficult to find spores to count and measure on the stained plates. Also, at later time intervals, 192 and $384 \mathrm{~h}$, some beetle mortality occurred, decreasing our sample sizes. For these reasons, some percent germination and germ tube lengths at some
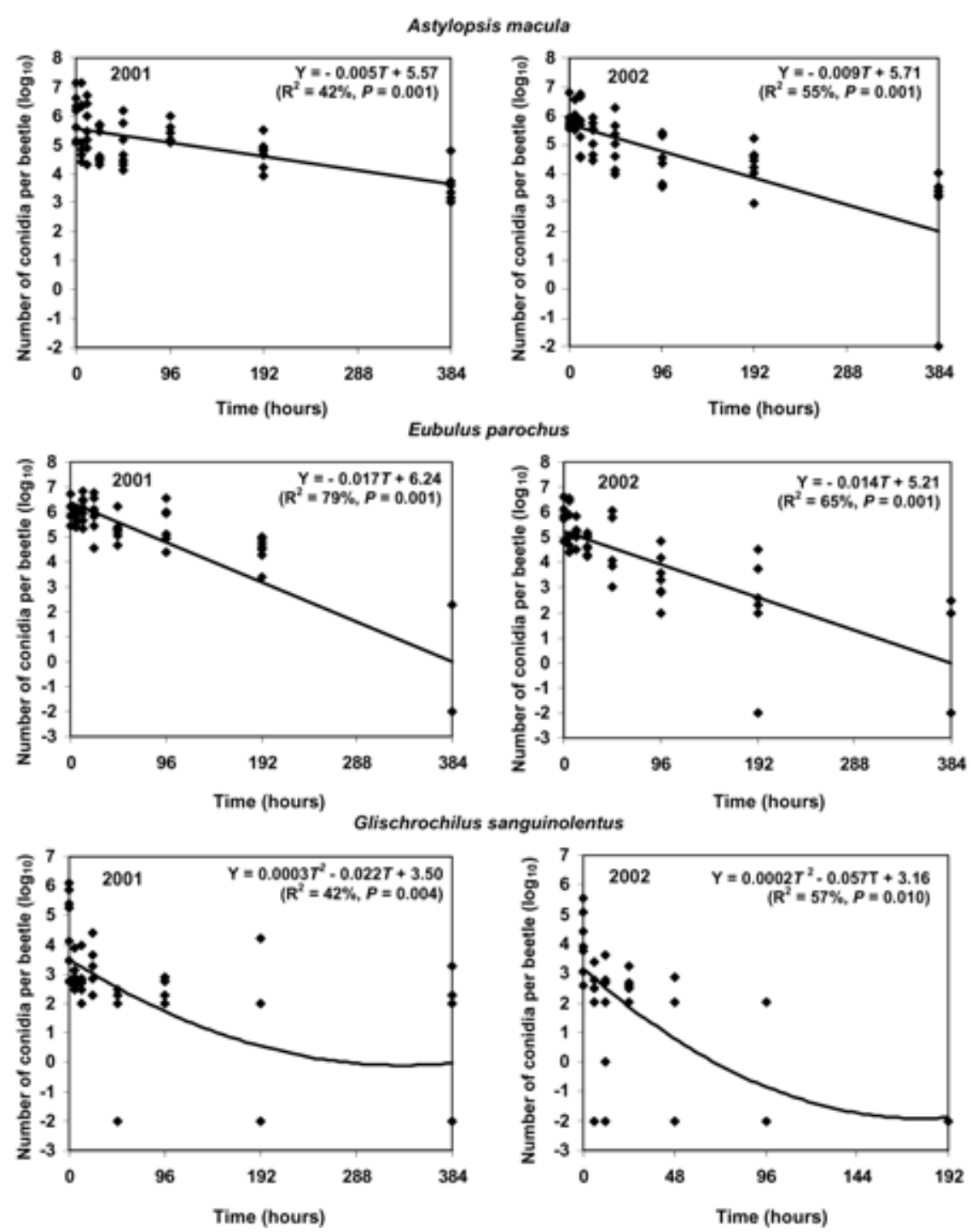

Fig. 2. Regression curves for the decrease in number of Sirococcus clavigignenti-juglandacearum conidia rinsed from artificially infested Astylopsis macula, Eubulus parochus, and Glischrochilus sanguinolentus over time in 2001 and 2002. Number of conidia per beetle was transformed using a $\log _{10}$ transformation and is displayed on the y-axis. Data are described by the equations on each graph in which $Y=$ number of conidia rinsed over time (transformed data) and $T=$ time in hours. 
time intervals were not included in the analyses. Percent germination and germ tube lengths of conidia collected from $G$. sanguinolentus, 192 and $384 \mathrm{~h}$ after inoculation in 2001 and 24, 48, 96, 192, and $384 \mathrm{~h}$ after inoculation in 2002, were not included in analyses. Percent germination data collected for conidia washed from $E$. parochus $384 \mathrm{~h}$ postinoculation in 2001 were not tube length data collected from A. macula samples collected $384 \mathrm{~h}$ after inoculation in 2001 and from E. parochus 192 and $384 \mathrm{~h}$ postinoculation in 2002 were not included. The $384 \mathrm{~h}$ time interval is not included in Figures 3 and 4, showing percent germination of conidia and germ tube length.

A percentage of $S$. clavigignenti-juglandacearum conidia germinated in every sample for each beetle species. Conidia rinsed from one individual of $G$. sanguinolentus germinated after $384 \mathrm{~h}$; however, included in the analyses. Similarly, germ

because of the small sample size, this data point was not included in the analyses. Percent germination was different between years for A. macula, E. parochus, and $G$. sanguinolentus $(P=0.001, P=0.001$, and $P=0.007$, respectively). In 2001, the mean percent germination over time decreased significantly for E. parochus and G. sanguinolentus $(P=0.001$ and $P=0.002$, respectively), but was consistent for $A$. macula $(P=0.480)$ (Fig. 3). Conidia rinsed from A. macula had the lowest overall mean percent germination in both years; however, mean percent germination of conidia carried by this species increased as time increased $(P=0.001)$, ranging from $28 \%$ at $0 \mathrm{~h}$ to $75 \%$ at $384 \mathrm{~h}$ in 2002 . In 2002, the mean percent germination over time was consistent for E. parochus $(P=0.110)$ and decreased significantly over time for $G$. sanguinolentus $(P=$ 0.001). In 2002, mean percent germination
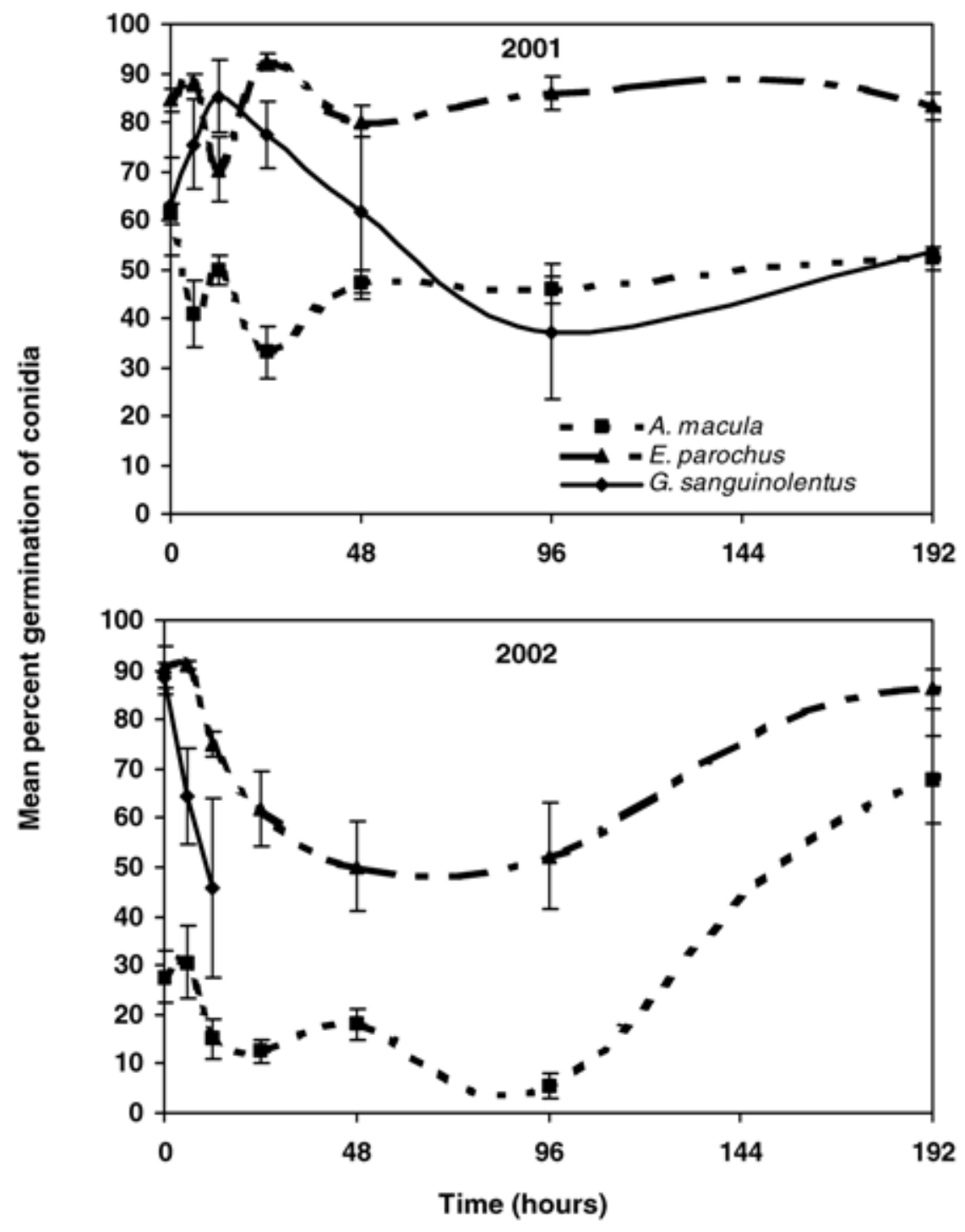

Fig. 3. Mean percent germination of Sirococcus clavigignenti-juglandacearum conidia rinsed from artificially inoculated Astylopsis macula, Eubulus parochus, and Glischrochilus sanguinolentus at each sample time interval (hours postinoculation) in 2001 and 2002; conidia incubated at $20^{\circ} \mathrm{C}$ for 30 h. Data for G. sanguinolentus were not collected for $384 \mathrm{~h}$ in 2001 and for $24,48,96,192$, and $384 \mathrm{~h}$ in 2002. Bars represent the standard error for each sample time within species. Some sample times, those with missing error bars, only had one replication and were not included in the analyses. of conidia rinsed from $E$. parochus ranged from $90 \%$ at $0 \mathrm{~h}$ to $60 \%$ at $384 \mathrm{~h}$ and mean percent germination of conidia rinsed from G. sanguinolentus ranged from $87 \%$ at $0 \mathrm{~h}$ to $46 \%$ at $12 \mathrm{~h}$ (Fig. 3 ).

Significant differences in germ tube length data were observed among species and between years. The overall mean germ tube lengths of conidia rinsed from $A$. macula were statistically similar for both years $(P=0.095)$ and there were no significant differences in germ tube lengths over time in 2001 and $2002(P=0.150$ and $P=0.650$, respectively) (Fig. 4). Germ tube lengths of conidia rinsed from $E$. parochus and $G$. sanguinolentus were not similar between years $(P=0.022$ and $P=$ 0.001 , respectively). In 2001, germ tube lengths of conidia rinsed from E. parochus significantly decreased in length as time increased $(P=0.025)$. However, in 2002, as time increased, germ tubes lengths significantly increased $(P=0.001)$ (Fig. 4). Germ tube lengths of conidia rinsed from $G$. sanguinolentus significantly decreased as time increased $(P=0.005)$ in 2001 , but were constant as time increased in 2002 $(P=0.504)$ (Fig. 4).

Scanning electron microscopy. Variations in the morphology of the beetles' exoskeletons were observed using SEM. A. macula and $G$. sanguinolentus had setae and pit-like structures on their exoskeletons (Figs. 5B and 5F). In contrast, E. parochus had an exoskeleton made up of scales housed in depressions that give the impression of increased surface area compared with the pit/seta morphology on the other species (Fig. 5D).

On the artificially inoculated specimens of A. macula, E. parochus, and G. sanguinolentus, conidia were commonly found on the ventral side of the thorax and abdomen and were less common on the legs and tarsi (Figs. 5B, D, and G). No conidia were observed on the mouth parts. Although conidia were not counted, SEM observations indicated that similar densities of conidia were found on the exoskeletons of all three species. Conidia were often found grouped on the exoskeleton in dense masses (Fig. 5F).

Field-collected specimens of A. macula and $E$. parochus were also examined using SEM for the presence of conidia of $S$. clavigignenti-juglandacearum. Ten beetles of each species were examined, and 4 of 20 individuals, 3 A. macula and 1 E. parochus, were found carrying conidia on their exoskeletons. Conidia were located on the ventral side of the abdomen (Figs. 6A and B) and thorax. None of these beetles were observed to have conidia on their legs, tarsi, or mouth parts. Conidia were not found clustered in high densities but were scattered or found singly (Fig. 6A and B).

\section{DISCUSSION}

Insect vectors have the potential to carry large numbers of viable fungal spores on 
their exoskeletons for long time periods. Field studies by Juzwik (7) found the nitidulid, Glischrochilus quadrisignatus Olivier, carried up to 69,000 spores of the oak wilt fungus, Ceratocystis fagacearum (Bretz) Hunt. The bark beetle, Scolytus multistriatus F. was found to carry more than 300,000 spores of Ophiostoma ulmi Buisiman (20), and in laboratory conditions, the convergent lady beetle (Hippodamia convergens Guérin-Méneville) carried viable spores of the dogwood anthracnose fungus (Discula destructiva Redlin) for at least 16 days (3).

Our study showed that artificially inoculated A. macula and E. parochus can potentially carry large numbers of $S$. clavigignenti-juglandacearum conidia, but the numbers carried decreased over time. Individuals of A. macula and E. parochus were able to initially carry up to 14 million and 5 million conidia, respectively, and retained conidia up to 16 days. Our results for the nitidulid, $G$. sanguinolentus, were similar to those of Juzwik and French (8). They found that individuals of $G$. sanguinolentus could carry up to 760,000 spores of the oak wilt fungus, but they did not report changes in spore numbers over time. In our study, individuals of $G$. sanguinolentus initially carried up to one million conidia of $S$. clavigignenti-juglandacearum and carried viable conidia for 16 days, but spore numbers decreased substantially with time.

In general, we found that fewer conidia were carried by $G$. sanguinolentus compared with the other two insect species, which may have been a result of beetle size and behavior. G. sanguinolentus is smaller than are A. macula or E. parochus. Therefore, A. macula and E. parochus have a greater surface area on which to collect and carry more conidia. Cease and Juzwik (1) found that larger-bodied species of nitidulids had a higher incidence and could carry a greater number of Ceratocystis fagacearum conidia than smaller-bodied species of nitidulids.

Behavioral differences may also have accounted in part for the variation in the number of $S$. clavigignenti-juglandacearum conidia rinsed from each species. We observed sporulating pycnidia of $S$. clavigignenti-juglandacearum growing only on the surface of the agar in plates used to inoculate the beetles. A. macula and $E$. parochus were observed crawling across the surface of the plates and readily contacted sporulating pycnidia. However, nitidulids have dorso-ventral flattened bodies which allow them to slip and burrow into small crevices (20). This burrowing behavior was observed during the 24-h infestation period. Individuals of $G$. sanguinolentus tended to tunnel into the agar of inoculation plates rather than continuing to crawl and remaining in contact with pycnidia on the surface of the medium. Furthermore, individuals of G. san- guinolentus were also observed burrowing into the pieces of apple fed to them during the trials; conidia may have been dislodged from their exoskeletons during this feeding behavior. This may account in part for the relatively greater loss of conidia by $G$. sanguinolentus over time compared with the other two test species.

Variations in exoskeleton morphology among the beetle species may also lead to differences in the number of conidia ac- quired and retained over time. E. parochus retained fewer conidia between $0 \mathrm{~h}$ and $384 \mathrm{~h}$ than $\operatorname{did}$ A. macula. The exoskeletons of A. macula and G. sanguinolentus have pits and setae distributed along the ventral surface of the abdomen and thorax, while the exoskeleton of E. parochus has scales seated in depressions. Conidia accumulated in the pits and around the setae on the exoskeletons of A. macula where they may have been less prone to dislodging,
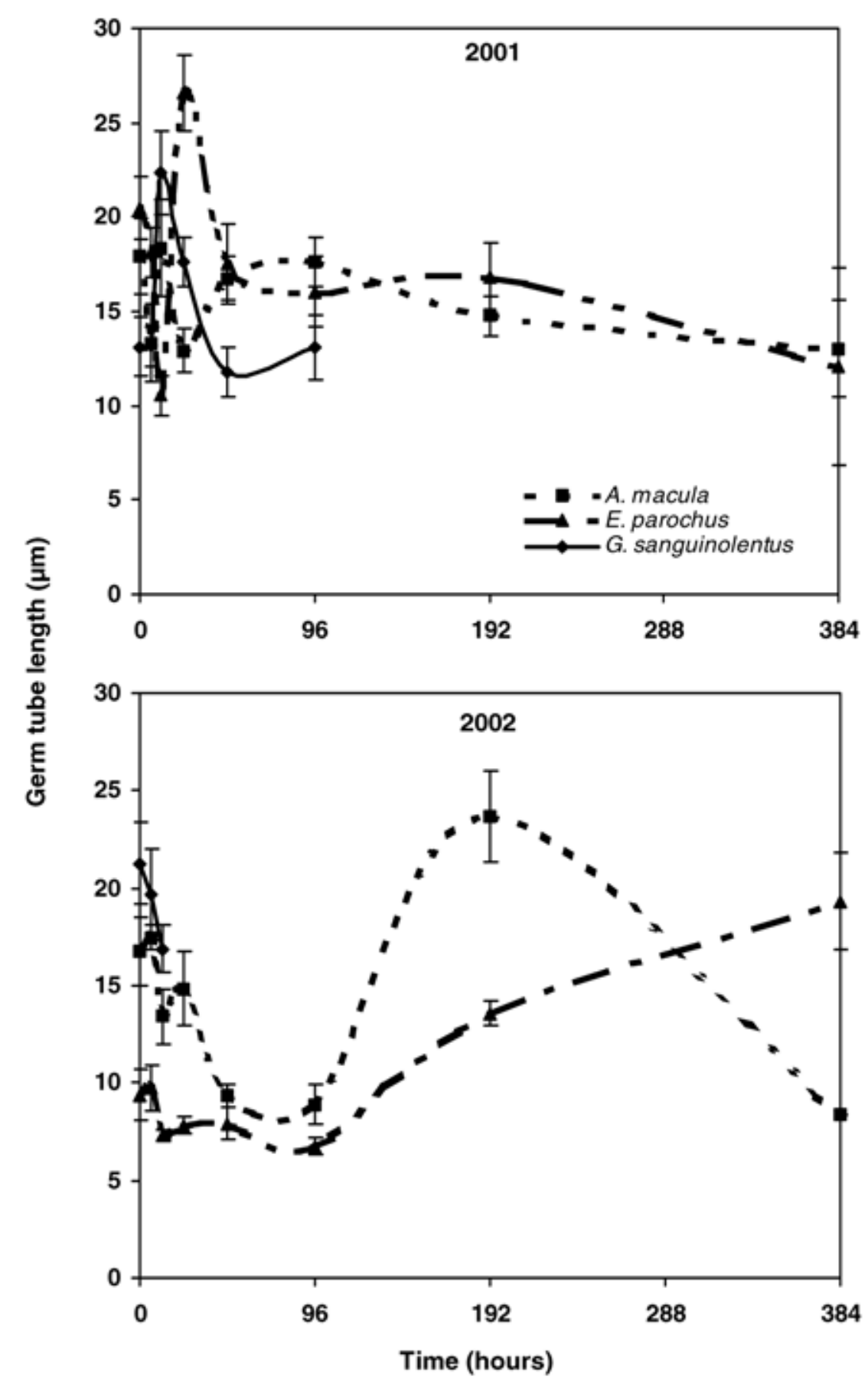

Fig. 4. Mean germ tube length (in micrometers) of Sirococcus clavigignenti-juglandacearum conidia rinsed from artificially inoculated Astylopsis macula, Eubulus parochus, and Glischrochilus sanguinolentus at each sample time (hours postinoculation); germ tubes measured after $30 \mathrm{~h}$ of growth at $20^{\circ} \mathrm{C}$. Data presented for 2001 and 2002. Data for G. sanguinolentus were not available for 192 and $384 \mathrm{~h}$ in 2001 and for 24, 48, 96, 192, and $384 \mathrm{~h}$ in 2002. Bars represent the standard error for each time interval within species. Some sample times, those with missing error bars, only had one replication and were not included in analyses. 
allowing this species to retain greater numbers of conidia over time than $E$. parochus. Some other known beetle vectors, such as the Douglas-fir bark beetle Dendroctonus pseudotsugae Hopk. and the bark beetle Scolytus scolytus F., have setal pits and setae on their elytra, abdomen, and thorax that are similar to those of $A$. macula and $G$. sanguinolentus. Spores of pathogenic fungi have been documented to reside within these types of pits and crevices $(14,20)$. When examining dissemination of the dogwood anthracnose fungus, Colby and Windham (2) also found conidia randomly scattered or lodged within pits on the exoskeleton of the convergent lady beetle.

Conidia that are lodged into these pits may remain on the exoskeleton for longer time periods than they do on smoother surfaces, and therefore, this seta/pit mor-

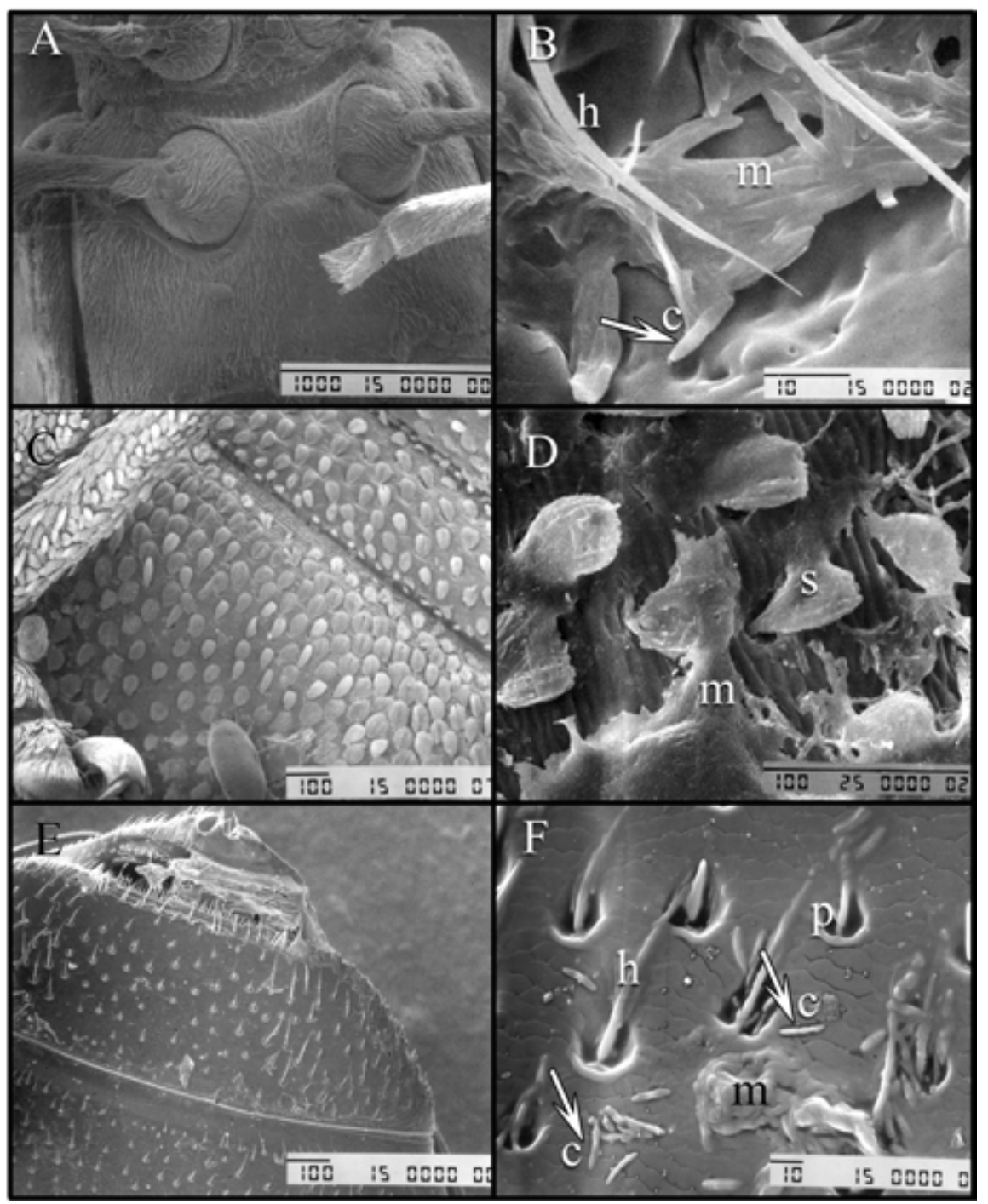

Fig. 5. Scanning electron photomicrographs of artificially inoculated Astylopsis macula, Eubulus parochus, and Glischrochilus sanguinolentus showing conidia of Sirococcus clavigignentijuglandacearum. All photomicrographs show the ventral side of the specimens. A, The thorax of $A$. macula at $\times 50$. B, The abdomen of A. macula at $\times 2000$. C, The abdomen of E. parochus at $\times 100$. D, The abdomen of $E$. parochus at $\times 500$. E, The abdomen of $G$. sanguinolentus at $\times 100$. $\mathbf{F}$, The abdomen of $G$. sanguinolentus at $\times 500$. Arrows highlight conidia of $S$. clavigignenti-juglandacearum. Conidia adhered to exoskeletons as a sticky mass (m). The exoskeleton of E. parochus is made up of scales (s), and the exoskeletons of A. macula and G. sanguinolentus are made up of pits (p) and setae (h). skeleton may have prolonged spore longevity. The sticky matrix may protect conidia from varying moisture levels and allow them to remain viable on the exoskeleton in a dormant state. Conidia of $S$. clavigignenti-juglandacearum were observed to remain viable for at least $32 \mathrm{~h}$ when stored at $35 \%$ relative humidity and $13^{\circ} \mathrm{C}$ (17). It has been suggested that conidia of $S$. clavigignenti-juglandacearum may become dormant through desiccation at low relative humidities and thus remain viable for a long time (17).

We found considerable variation in our conidial viability measures over time between the two years. (Figs. 3 and 4). There are several possibilities to explain these differences. Experimental variation caused by smaller sample sizes at the later time intervals may have skewed our data. As the number of conidia on each insect decreased with time, it was more difficult to find and measure germ tubes of viable spores. Laboratory conditions in 2001 and 2002 were experimentally similar; however, there may have been some unknown differences that altered growing conditions for conidia in 2002. Furthermore, the behavior of beetles collected each year may have varied. Halik and Bergdahl (6) observed that during drier summers, $A$. mac$u l a$ and $E$. parochus carried more conidia, suggesting spores were used as a source of moisture by the insects (6). Field environmental variations in 2001 and 2002 prior to beetle collection may have affected the behavior of the insects, altering conditions for carried conidia.

The focus of this study was to determine the number of viable $S$. clavigignenti-jug landacearum conidia that beetle vectors could carry over time. A. macula carried the greatest number of conidia at 16 days A. macula and E. parochus carried greater numbers of conidia overall than $\operatorname{did} G$. sanguinolentus. This trend was also observed when field-collected insects were examined for the presence of $S$. clavigignenti-juglandacearum conidia (6). $A$. macula and $E$. parochus have been shown to carry great numbers of conidia under natural conditions, up to 1.6 million and 780,000, respectively. Thus, it may appear that these two species are potentially more efficient vectors of the butternut canker fungus. However, to be an effective vector of a pathogen, life cycles of the insect and fungus need to coincide in time and space. The insect must visit diseased and healthy trees regularly with viable inoculum at times when environmental conditions are optimal for dissemination and infection (13). A. macula and $E$. parochus are known to feed on the bark of dead and dying stems and branches of butternut as well as on the fungus. They have been found in living crowns of butternut but may be feeding only within diseased portions of the living crown (6). It is not yet known whether these species read- 
ily feed on healthy stems and branches of butternut trees.

Halik and Bergdahl (6) determined that populations of A. macula and E. parochus peaked at different times throughout the growing season. E. parochus was found earlier in the spring and summer, with populations peaking in May and June and again in late summer. Individuals of $E$. parochus were found carrying conidia more often during May and June. A. macula was found from June to August, with populations peaking in July, and individuals carried conidia of $S$. clavigignenti-juglandacearum throughout this period. Since life cycles of these insects overlap during the summer, vectoring by at least one of these species could occur throughout the entire growing season (6).

$G$. sanguinolentus has been observed feeding within wounds on healthy portions of butternut. Although this species appears to carry fewer $S$. clavigignenti-juglandacearum conidia, it may have a greater capacity to cause new infections because of its burrowing behavior and attraction to cankers and wounds $(6,9)$.
It is still unclear what role these insect species play in the disease cycle of butternut canker. However, the rapid rate of spread of $S$. clavigignenti-juglandacearum throughout the range of butternut suggests that some means of long-distance dissemination must exist. If beetles associated with butternut can carry viable conidia of $S$. clavigignenti-juglandacearum for at least $384 \mathrm{~h}$, this increases the potential for new infections to occur as these beetles preferentially seek butternut for feeding and oviposition. A more complete understanding of the life cycles of these insects will allow us to better determine the vector role each species may play in the dissemination of $S$. clavigignenti-juglandacearum.

\section{ACKNOWLEDGMENTS}

This work was funded in part by the USDA McIntire-Stennis Cooperative State Research Program, the Northern Nut Growers Association, and the University of Vermont. We thank A. Howard for statistical advice, M. VonTurkovich for technical advice and assistance in preparation of specimens for SEM studies, and C. Adams for laboratory and field assistance. This article is prepared as partial fulfillment for the degree of Master of Science for

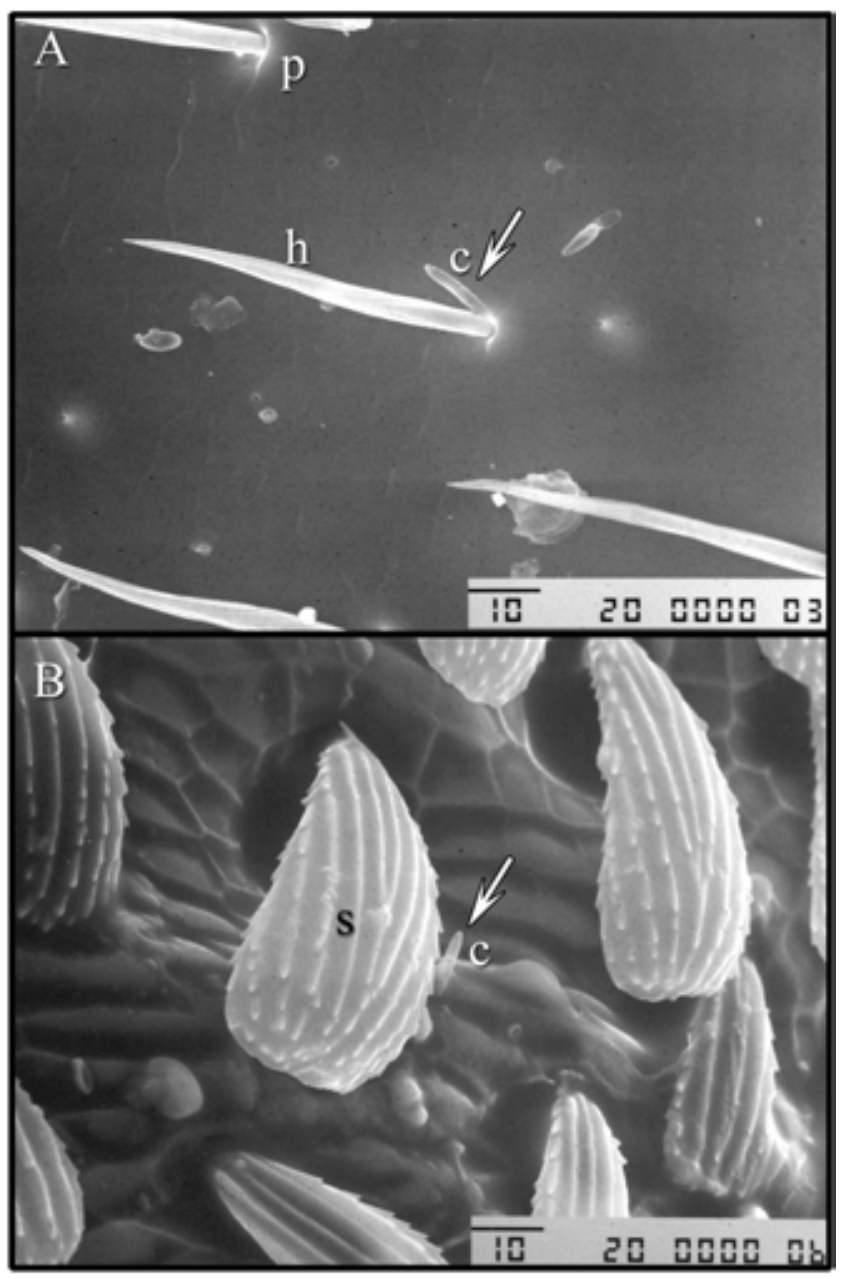

Fig. 6. Scanning electron photomicrographs showing the ventral side of abdomens of field-collected Astylopsis macula and Eubulus parochus with conidia of Sirococcus clavigignenti-juglandacearum. A, The abdomen of A. macula at $\times 1000$. The exoskeleton of A. macula is made up of pits (p) and setae (h). B, The abdomen of E. parochus at $\times 1000$. The exoskeleton of E. parochus is made up of scales (s). Arrows highlight conidia (c) of $S$. clavigignenti-juglandacearum.

J. Stewart from The Rubenstein School of Environment and Natural Resources at the University of Vermont.

\section{LITERATURE CITED}

1. Cease, K. R., and Juzwik, J. 2001. Predominant nitidulid species (Coleoptera: Nitidulidae) associated with spring oak wilt mats in Minnesota. Can. J. For. Res. 31:635-643.

2. Colby, D., and Windham, M. T. 1995. Hippodamia convergens dissemination of dogwood anthracnose fungus (Melanconiales: Melanconeacae). Environ. Entomol. 24:1075-1079.

3. Colby, D., Windham, M. T., and Grant, J. F. 1996. Transportation and viability of conidia of Discula destructiva on Hippodamia convergens. Plant Dis. 80:804-805.

4. Furniss, M. M., Solheim, H., and Christiansen, E. 1990. Transmission of blue-stain fungi by Ips typographus (Coleoptera: Scolytidae) in Norway spruce. Ann. Entomol. Soc. Am. 83:712-716.

5. Halik, S., and Bergdahl, D. R. 1996. Sirococcus clavigignenti-juglandacearum isolated from beetles collected from Juglans cinerea. (Abstr.) Phytopathology 86(suppl.):S122.

6. Halik, S., and Bergdahl, D. R. 2002. Potential beetle vectors of Sirococcus clavigignenti-juglandacearum on butternut. Plant Dis. 86:521527.

7. Juzwik, J., Cease, K. R., and Meyer, J. M. 1998. Acquisition of Ophiostoma quercus and Ceratocystis fagacearum by nitidulids from $O$. quercus-colonized oak wilt mats. Plant Dis. 82:239-243.

8. Juzwik, J., and French D. W. 1983. Ceratocystis fagacearum and $C$. piceae on the surfaces of free-flying and fungus-mat-inhabiting nitidulids. Phytopathology 73:1164-1168.

9. Katovich, A., and Ostry, M. E. 1998. Insects associated with butternut and butternut canker in Minnesota and Wisconsin. Gt. Lakes Entomol. 31:98-108.

10. Kuntz, J. E., and Nair, V. M. 1982. The role of hyphal pegs in spore dissemination by Sirococcus clavigignenti-juglandacearum. (Abstr.) Phytopathology 72:1137.

11. Landis, J. N. 1998. Butternut canker in Vermont: Statistical analysis of survey and spatial data. M.S. thesis. University of Vermont, Burlington.

12. Landis, J. N., and Bergdahl, D. R. 1996. Incidence of butternut canker spatially related to tree density. (Abstr.) Phytopathology 86(suppl.):S123.

13. Leach, J. G. 1940. Insect Transmission of Plant Diseases. McGraw-Hill, New York.

14. Lewinsohn, D., Lewinsohn, E., Bertagnolli, C. L, and Patridge, A. D. 1994. Blue-stain fungi and their transport structures on the Douglasfir beetle. Can. J. For. Res. 24:2275-2283.

15. Livingstone, R. L., and Berryman, A. A. 1972 Fungus transport structures in the fir engraver, Scolytus ventralis (Coleoptera: Scolytidae) Can. Entomol. 104:1793-1800.

16. Nicholls, T. H. 1979. Butternut canker. Pages 73-82 in: Walnut Insects and Diseases, Workshop Proceedings. U.S. Dep. Agric. For. Serv. Gen. Tech. Rep. NC-52.

17. Tisserat, N., and Kuntz, J. E. 1983. Longevity of conidia of Sirococcus clavigignenti-juglandacearum in a simulated airborne state. Phytopathology 73:1628-1631.

18. Tisserat, N., and Kuntz, J. E. 1983. Dispersal gradients of conidia of the butternut canker fungus in a forest during rain. Can. J. For. Res. 13:1139-1144.

19. Tuite, J. 1969. Plant Pathological MethodsFungi and Bacteria. Burgess Publishing Co, Minneapolis, MN.

20. Webber, J. F., and Gibbs, J. N. 1989. Insect Dissemination of Fungal Pathogens of Trees: Insect Fungus Interactions. Academic Press, London. 